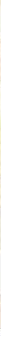

\title{
A Obrigação do Estado na Promoção do Bem Comum Por Meio de Políticas Tributárias de Incentivo à Preservação do Meio Ambiente
}

The Obligation of The State to Promote the Commom Good By Means of Tax Policies to Encourage The Preservation of The Environment

La Obligación del Estado en la Promoción del Bien Común Por Medio de Políticas Tributarias de Incentivo a la Preservación del Medio Ambiente 


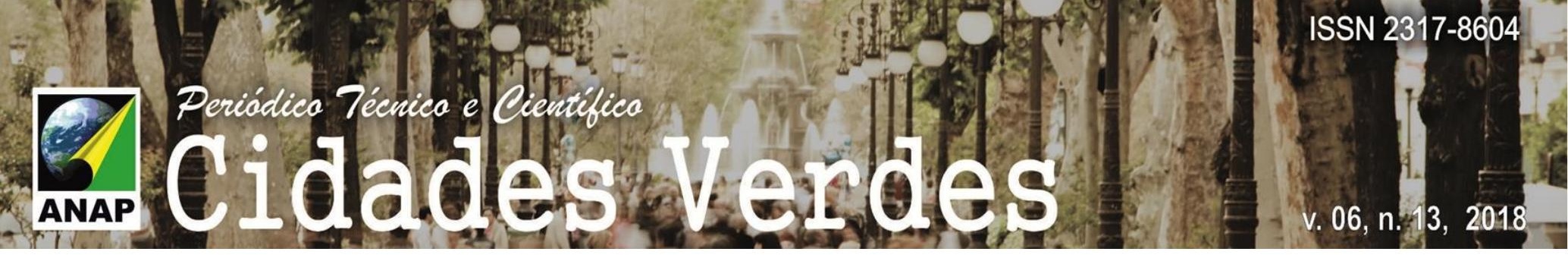

RESUMO

Este trabalho tem por objeto demonstrar a obrigação constitucional imposta ao Estado e à coletividade de preservar o meio ambiente ecologicamente saudável para as presentes e futuras gerações, por meio da priorização do bem comum, em detrimento de interesses particulares; bem como apresentar algumas soluções viáveis para incentivar a participação da população nas questões ambientais. Toma-se como ponto de partida para esta participação as políticas públicas educacionais; a possibilidade de redução de carga tributária, a promoção de incentivos fiscais e benefícios de modo que possam garantir a conscientização pela proteção do meio ambiente e praticando a integração entre Poder Público e sociedade civil. Ademais, o presente trabalho demonstrará que a concessão de benefícios de ordem fiscal não ofendem qualquer dispositivo legal, sob o ponto de vista da responsabilidade do administrador público, e que a concessão de referidos benefícios não só é plenamente aplicável como economicamente viável, podendo gerar ganhos ambientais a médio e longo prazos se despertados em todos os envolvidos conceitos científicos e legislativos capazes de implementar tais medidas.

PALAVRAS-CHAVE: Meio Ambiente. Tributos. Gestão Pública

\begin{abstract}
This paper aims to demonstrate the constitutional obligation imposed on the State and the community to preserve the ecologically healthy environment for present and future generations, through the prioritization of the common good, to the detriment of private interests; as well as to present some viable solutions to encourage the participation of the population in environmental issues. Public education policies are taken as a starting point for this participation; the possibility of reducing the tax burden, promoting tax incentives and benefits so that they can guarantee awareness for the protection of the environment and practicing the integration between Public Power and civil society. In addition, the present study will demonstrate that the granting of fiscal benefits does not offend any legal provision, under the responsibility of the public administrator, and that the granting of said benefits is not only fully applicable but economically viable, and can generate gains environmental issues in the medium and long term have aroused in all involved scientific and legislative concepts capable of implementing such measures.
\end{abstract}

KEY WORDS: Environment. Taxes. Public Administration.

\title{
RESUMEN
}

Este trabajo tiene por objeto demostrar la obligación constitucional impuesta al Estado ya la colectividad de preservar el medio ambiente ecológicamente sano para las presentes y futuras generaciones, por medio de la priorización del bien común, en detrimento de intereses particulares; así como presentar algunas soluciones viables para fomentar la participación de la población en las cuestiones medioambientales. Se toma como punto de partida para esta participación las políticas públicas educativas; la posibilidad de reducción de carga tributaria, la promoción de incentivos fiscales y beneficios de modo que puedan garantizar la concientización por la protección del medio ambiente y practicando la integración entre el Poder Público y la sociedad civil. Además, el presente trabajo demostrará que la concesión de beneficios de orden fiscal no ofende ningún dispositivo legal, desde el punto de vista de la responsabilidad del administrador público, y que la concesión de dichos beneficios no sólo es plenamente aplicable como económicamente viable, pudiendo generar ganancias ambientales a medio y largo plazo se despiertan en todos los involucrados conceptos científicos y legislativos capaces de implementar tales medidas.

PALABRAS CLAVE: Medio Ambiente. Impuestos. Gestión Pública. 


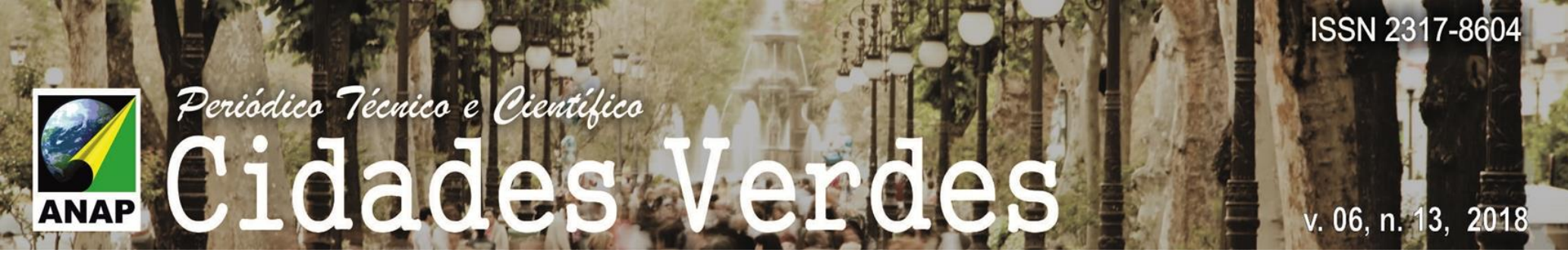

\section{INTRODUÇÃO}

Ao longo de toda a história da humanidade o ser humano vem degradando o meio ambiente de maneira predatória e sem qualquer planejamento colocando em risco a sua própria sobrevivência neste planeta. Os necessários avanços tecnológicos ocorrem de maneira cada vez mais acelerada e a constante busca dos altos lucros, pela atividade empresarial, principalmente durante após a Revolução Industrial, acabaram por causar danos ambientais de incerta e improvável reparação.

Somente em meados da década de setenta é que o homem passa a reconhecer o nível da destruição que causou ao planeta e iniciou um processo de busca de alternativas a fim de frear a degradação descontrolada e promover a prática sustentável no uso dos recursos naturais.

Este processo de reconhecimento de responsabilidade ambiental mobilizou vários países na busca de alternativas que ganharam legitimidade com as Conferências de Estocolmo (1972) e Tbilissi (1977) e, com isso, os Estados passaram a implantar legislações aplicando restrições e limitações ao uso de recursos naturais de modo a garantir uma sadia qualidade de vida e a existência das futuras gerações.

No Brasil, do ponto de vista legislativo, essa consciência só se manifestou com a promulgação da Constituição Federal de 1988 que em seu art. 225 colocou o meio ambiente como bem de uso comum do povo e essencial à sadia qualidade de vida atribuindo a responsabilidade pela sua preservação ao próprio Poder Público e à toda coletividade, culminando na realização da ECO-92 e a RIO+20.

Sob essa ótica, o presente trabalho tem por principal objetivo a investigação dos motivos que levaram a imposição do compartilhamento dessa responsabilidade, bem como analisar quais as políticas públicas que estão sendo implantadas de maneira eficaz para que seja aplicado o dispositivo constitucional em sua plenitude.

\section{DOS DEVERES DO ESTADO: O BEM COMUM}

A Constituição Federal de 1988 estabelece em seu art. 3o que os objetivos fundamentais da República Federativa do Brasil são: "I - construir uma sociedade livre, justa e solidária; II garantir o desenvolvimento nacional; III - erradicar a pobreza e a marginalização e reduzir as desigualdades sociais e regionais e IV - promover o bem de todos, sem preconceitos de origem, raça, sexo, cor, idade e quaisquer outras formas de discriminação."

De fato, nota-se que são objetivos nobres e que, nem de longe, se mostram exagerados ou inexequíveis sob a ótica da Dignidade da Pessoa Humana, haja vista que tais objetivos obedecem a parâmetros mínimos para garantir a dignidade de todas as pessoas que aqui habitam.

Ademais, além dos objetivos previstos no art. 3 de nossa carta política, o Estado assume outras obrigações de cunho social perante seu povo tal como educação, saúde, alimentação, trabalho, moradia, transporte, lazer, segurança, previdência social, proteção à maternidade e à 


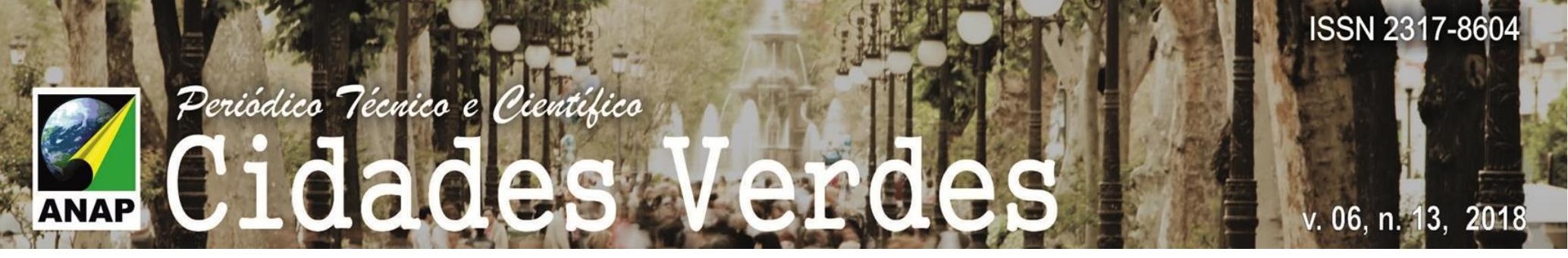

infância e assistência aos desamparados, tudo conforme disposto no art. 60 do mesmo texto constitucional.

Todos os objetivos que devem ser alcançados pela República Federativa do Brasil, repousam sob o manto fundamental da consecução do bem comum, ou seja, atuar com políticas sócioeconômicas e políticas educacionais que sempre priorizem alcançar o maior benefício à toda sociedade.

Esse dever atribuído ao Estado não é conceito novo, e sim o próprio fundamento de existência desse ente jurídico criado pela união de esforços da sociedade, que por meio da soberania cria as normas de conduta necessárias para administrar um determinado povo localizado em determinado território.

O Papa João XXIII publicou a Encíclica Pacem in Terris em 11 de Abril de 1963, um documento de fortíssimo apelo social, que convoca o poder do Estado de forma constante a promover a paz e o bem de todos como fundamento da existência humana.

À época do pontificado do Papa João XXXIII acusavam-no de ser maçom, radical esquerdista e herege modernista por ter convocado o Concílio Vaticano II, promovido a liberdade religiosa e o ecumenismo. Enfim, foi um líder religioso importante que em seu curto período diante de uma instituição tão apegada às suas tradições, iniciou um processo de renovação tendo por fundamento o bem de todos.

Muitos textos constitucionais, inclusive o texto brasileiro, passaram a adotar o conceito estabelecido pelo religioso que no verso 58 da Encíclica menciona: "O bem comum consiste no conjunto de todas as condições de vida social que consintam e favoreçam o desenvolvimento integral da personalidade humana".

Como se vê, não é feita referência a uma espécie particular de bens, indicando-se, em lugar disso, um conjunto de condições, incluindo a ordem jurídica e a garantia de possibilidades que consintam e favoreçam o desenvolvimento integral da personalidade humana.

Conforme Dallari $(2006$, p.24) ao se afirmar, portanto, que a sociedade humana tem por finalidade o bem comum, isso quer dizer que ela busca a criação de condições que permitam a cada homem e a cada grupo social a consecução de seus respectivos fins particulares. Quando uma sociedade está organizada de tal modo que só promove o bem de uma parte de seus integrantes, é sinal de ela está mal organizada e afastada dos objetivos que justificam sua existência.

Deste modo, não resta dúvida de que o Estado é o grande responsável em promover o bem comum e, com isto, não se quer dizer que o Estado deva entregar todos os subsídios necessários ao povo sem a devida contrapartida, mas garantir todos os meios necessários para que TODOS os grupos sociais possam ter acesso aos recursos que precisam para alcançar seus objetivos.

\section{DOS RECURSOS ESTATAIS}

Em que pese a nobreza de toda a filosofia acerca da obrigatoriedade de o Estado promover o bem comum, é fato que nada surge sem a devida contrapartida. O Brasil é um país que existe sobre o princípio da livre iniciativa já demonstrado no artigo 3 o do diploma constitucional e 


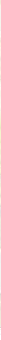

ratificado pelo art. 170 que trata justamente sobre os princípios que regem a Ordem Financeira e Econômica.

Por força do disposto no art. 173 da Constituição Federal, a exploração direta de atividade econômica pelo Estado só será permitida quando necessária aos imperativos da segurança nacional ou a relevante interesse coletivo, assim, como regra geral, o Estado não deve empreender no mercado de consumo de massa.

Como por exemplo, podemos citar a Caixa Econômica Federal (CEF) que exerce uma importante função social, haja vista que a iniciativa privada, por sempre almejar o lucro, não tem interesse em explorar o ramo financeiro nas regiões mais ermas do país.

Ademais, a C.E.F. também exerce sua função social como fator preponderante nas taxas de juros de empréstimos e financiamentos imobiliários à população de baixa renda.

Diante de tanta restrição para que o Estado se abasteça de recursos financeiros, não existe outra forma de o mesmo cumprir com os seus objetivos fundamentais previstos no art. 3 da Constituição Federal, a não ser convocando toda a coletividade para participar da consecução desses objetivos, custeando todo o aparelho necessário, daí a origem da tributação.

Assim, a própria população é quem financia o Estado por meio do pagamento de tributos que incidem sobre o seu patrimônio, renda ou serviços ou, ainda, sobre a necessidade de se atender algum tipo de interesse da sociedade como o Sistema Único de Saúde (SUS), pagamento de benefícios previdenciários ou assistenciais (INSS, LOAS, Bolsa Família e etc...).

Outrossim, reiteramos a ideia de que nada surge de maneira $100 \%$ gratuita. Tudo sai do bolso do contribuinte e, para ele, deve ser reinvestido por meio de serviços públicos de qualidade.

A tributação é a forma suprema com a qual o Estado consegue encher o seu cofre de recursos necessários para a consecução do bem comum, e a população brasileira, em especial, tem uma carga tributária elevadíssima, o que não justifica a baixa qualidade dos serviços públicos colocados à sua disposição, tampouco o descaso do Estado com os mais necessitados.

Em 2016, a Carga Tributária Bruta (CTB) atingiu 32,38\%, contra 32,11\% em 2015, indicando variação positiva de 0,27 pontos percentuais (Tabela 01). Essa variação resultou da combinação dos decréscimos em termos reais de 3,5\% do Produto Interno Bruto e de 2,8\% da arrecadação tributária nos três níveis de governo ${ }^{1}$.

Note-se que são números consideráveis, dada a dimensão continental do país, e que não conseguem refletir a exatidão da carga tributária levando em consideração a complexidade de nosso sistema tributário.

Os dados foram extraídos de um órgão estatal que tem por objetivo a fiscalização e arrecadação de tributos federais e, por conta do pacto federativo e a não intervenção da União nos negócios dos estados membros e dos municípios, os quais são dotados de autonomia quanto aos tributos de sua administração, fica difícil acreditar que os números refletem a

${ }^{1}$ Disponível em http://idg.receita.fazenda.gov.br/dados/receitadata/estudos-e-tributarios-eaduaneiros/estudos-e-estatisticas/carga-tributaria-no-brasil/carga-tributaria-2016.pdf. Acesso em 14.05 .2018 as $15 \mathrm{~h} 05 \mathrm{~min}$ 


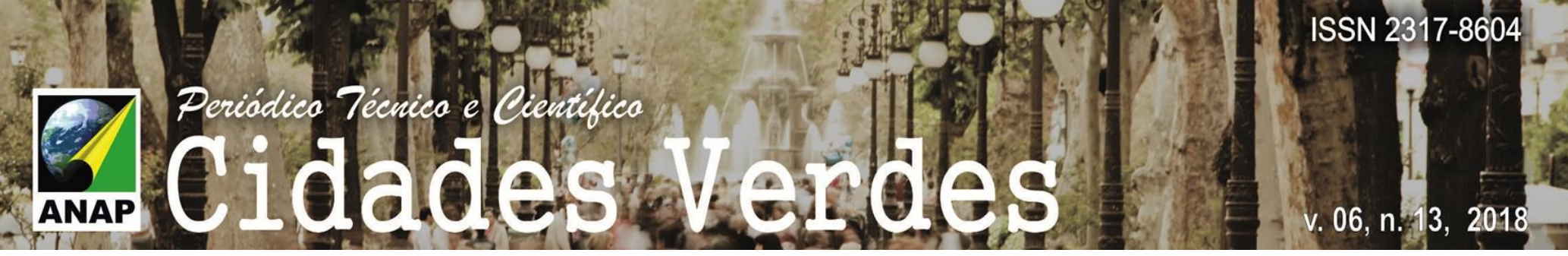

realidade levando qualquer leigo no assunto a concluir que a carga tributária total é ainda maior.

A Constituição Federal expressa que cada unidade federativa tem autonomia para legislar sobre três espécies tributárias: impostos, taxas e contribuições de melhoria; e cabe à União instituir outras duas: contribuições especiais e empréstimos compulsórios; todas fundamentadas nos arts. 145, 148 e 149 da Carta Magna, porém, a legislação federal permite, em alguns casos, a tributação sobre tributação (caso dos tributos sobre o consumo) cujo cálculo de valores podem ser apenas aproximados.

Diante de tal realidade, o contribuinte se sente desamparado pelo Estado, que no Brasil, se apropria de praticamente o valor total correspondente a 05 meses de tudo que o trabalhador comum recebe como salário a cada, visto que não recebe do Estado em forma de serviços a contribuição tributária que realiza. Observa-se na verdade que a população vive a sensação contrária ao efeito de bem comum; o Estado, desta forma, desestimula a ideia de coletividade e de participação popular na gestão do bem público.

\section{O DEVER DE CUIDADO COM O MEIO AMBIENTE}

A Constituição Federal consagra o direito de todos a um meio ambiente ecologicamente equilibrado, essencial à sadia qualidade de vida colocando-o sob a proteção da coletividade e do Poder Público. A este atribui numerosas incumbências, que evidentemente deverão ser exercidas dentro da esfera de competências própria a cada um. Quer dizer, ao Poder Público federal segundo a competência federal, ao estadual segundo a competência dos Estados, etc (FERREIRA FILHO, 2006, p. 372).

Nenhuma outra Constituição Brasileira trouxe qualquer dispositivo tratando da proteção ao meio ambiente sendo o texto de 1.988, pioneiro neste sentido, dando uma imensa importância à questões ambientais fazendo com que o termo "meio-ambiente" apareça por 18 vezes, a saber:

Art. 5, LXIII - Dá legitimidade ao cidadão para propositura de ação popular;

Art. 23, VI - Atribui responsabilidade de proteção à todas as entidades políticas;

Art. 24, VI e VIII - Competência legislativa à todos os entes exceto ao município para legislar sobre proteção e responsabilidade por danos ao meio ambiente;

Art. 129, III - Função institucional do Ministério Público para promover inquérito civil e ação civil pública para proteger o meio ambiente;

Art. 170, VI - Defesa do meio ambiente como princípio econômico;

Art. 174, §3ㅇ - Favorecimento de garimpeiros considerando proteção ao meio ambiente; 


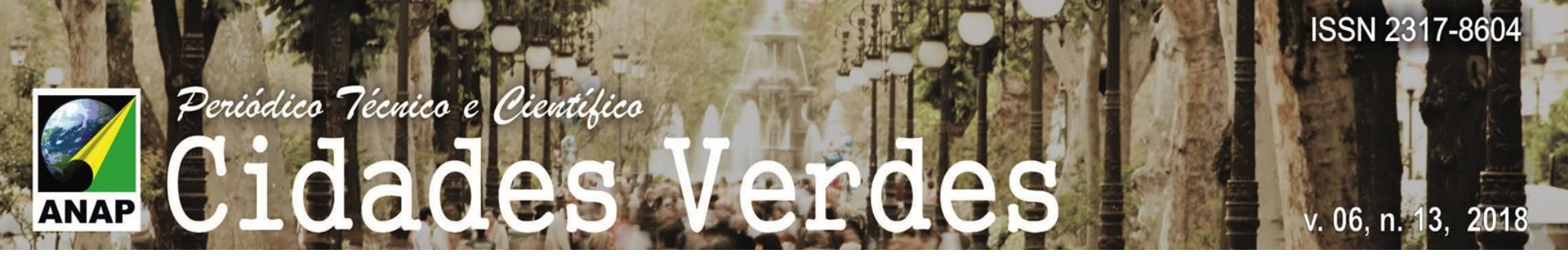

Art. 186, II - Função social da propriedade rural;

Art. 200, VIII- Atribuição do SUS proteger o meio ambiente do trabalho;

Art. 220, §30, II - Lei Federal deve regular atividade de comunicação que possa ser nociva ao meio ambiente;

Art. 225 e seguintes. Capítulo destinado ao meio ambiente com 8 aparições;

O fato do termo "meio ambiente" aparecer por tantas vezes em um texto constitucional não é mera coincidência. Na verdade é o reflexo de uma necessária preocupação do legislador com os impactos que o crescimento populacional e o avanço tecnológico causaram à condição humana depois da destruição dos recursos naturais do planeta de forma predatória, sem qualquer planejamento.

Por este motivo, o art. 225 da Constituição reconheceu que o meio ambiente é essencial à sadia qualidade de vida, porém não impôs apenas ao Estado a obrigatoriedade de sua manutenção, mas compartilhou este dever com toda a coletividade.

Outrossim, de nada adiantaria jogar tamanha responsabilidade ao cidadão sem oferecer qualquer ferramenta que este pudesse utilizar para a preservação desse direito essencial e, por esta razão, concedeu o direito de provocar o Poder Judiciário por meio da Ação Popular, caso note qualquer agressão ou ameaça ao meio ambiente.

Ademais, a preservação do meio ambiente é de interesse público, e ainda que haja algum tipo de interesse particular, em terras particulares, observadas todas as disposições acerca do direito de propriedade (que também é garantido constitucionalmente) o interesse público sempre deverá prevalecer.

Conforme Carvalho Filho (2017, p.55) o indivíduo tem que ser visto como integrante da sociedade, não podendo os seus direitos, em regra, ser equiparados aos direitos sociais. Vemos a aplicação do princípio da supremacia do interesse público, por exemplo, na desapropriação, em que o interesse público suplanta o do proprietário; ou no poder de polícia do Estado, por força do qual se estabelecem algumas restrições às atividades individuais.

Assim, de modo a garantirmos um meio ambiente saudável para as presentes e futuras gerações, é necessário conscientizar Estado e Povo de que o desenvolvimento precisa continuar, porém, de forma sustentável.

\section{EDUCAÇÃO AMBIENTAL}

A educação ambiental decorre do princípio da participação na tutela do meio ambiente, e, como acima mencionado, restou expressamente prevista na Constituição Federal, no seu art. $225, \S 1$ 으, VI. Buscou-se trazer consciência ecológica ao povo, titular do direito ao meio ambiente, permitindo a efetivação do princípio da participação na salvaguarda desse direito.

Além do já exposto, a Lei no 9.795/99 estabeleceu a Política Nacional de Educação Ambiental definindo-a como os processos pelos quais o indivíduo e a coletividade constroem valores 


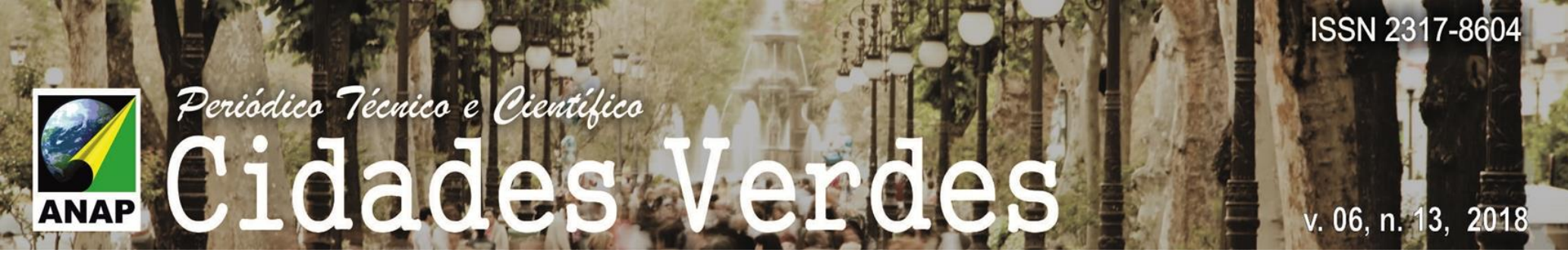

sociais, conhecimentos, habilidades, atitudes e competências voltadas para a conservação do meio ambiente.

A educação ambiental será implementada ainda, através de ações e práticas educativas voltadas à sensibilização da coletividade sobre as questões ambientais, à organização e participação na defesa da qualidade do meio ambiente.

A Política Nacional do Meio Ambiente veio a reforçar a ideia de que o meio ambiente deve ser defendido e preservado pelo Poder Público e pela coletividade (o que importa dizer que é um dever de todos, pessoas físicas e jurídicas), por intermédio da construção de valores sociais voltados à preservação desse bem pela implementação da educação ambiental.

\section{PARTICIPAÇÃO DE TODOS NA PRESERVAÇÃO AMBIENTAL}

Em que pese o fato de a Constituição Federal ter atribuído à todos, Poder Público e coletividade, o dever de preservar o meio ambiente para as presentes e futuras gerações, é inegável que mesmo depois de quase 30 anos dessa exigência ainda estamos gatinhando em medidas eficazes que possam materializar esse direito.

O Estado ainda é o grande responsável em fazer despertar na coletividade o dever de preservar o meio ambiente seja por meio das políticas públicas de natureza preventiva ou naquelas de caráter punitivo, voltadas às pessoas físicas ou jurídicas que, de alguma maneira, ofendem a integridade do meio ambiente.

Contudo, o que mais o Estado pode fazer de modo a despertar o interesse coletivo para as questões ambientais?

Existem políticas extremamente eficazes que vem sendo adotadas por diversos municípios de toda a federação que, dentro de suas atribuições constitucionais e, respeitando os limites estabelecidos pela Lei Complementar no 101/2000 (Lei de Responsabilidade Fiscal), vêm concedendo incentivos fiscais para aqueles que promovem práticas sustentáveis.

Alguns municípios renunciam ao direito de receber uma parcela das receitas oriundas de alguns impostos sob sua competência para que os contribuintes desenvolvam práticas ecológicas em seus imóveis, profissões, estabelecimentos e outros empreendimentos.

Tal renúncia de receita, desde que realizada nos parâmetros do art. 14 da Lei de Responsabilidade Fiscal, não afetam os repasses recebidos de outros entes (estado e União) e ainda geram ganhos e benefícios ambientais, bem como a economia alcançada pelo contribuinte ainda gera estímulo a práticas sustentáveis.

Grande exemplo disto é a implantação do IPTU verde, política municipal que concede descontos progressivos no referido imposto aos imóveis que desenvolvam atividades ecologicamente sustentáveis.

No município de Santa Isabel-SP, existe a Lei Complementar no 174/2015 a qual concede desconto de no mínimo $3 \%$ e no máximo de $20 \%$ ao IPTU do imóvel que contenha alguma das benfeitorias especificadas abaixo e com os seguintes parâmetros:

- Sistema de captação de água da chuva (4\%) 


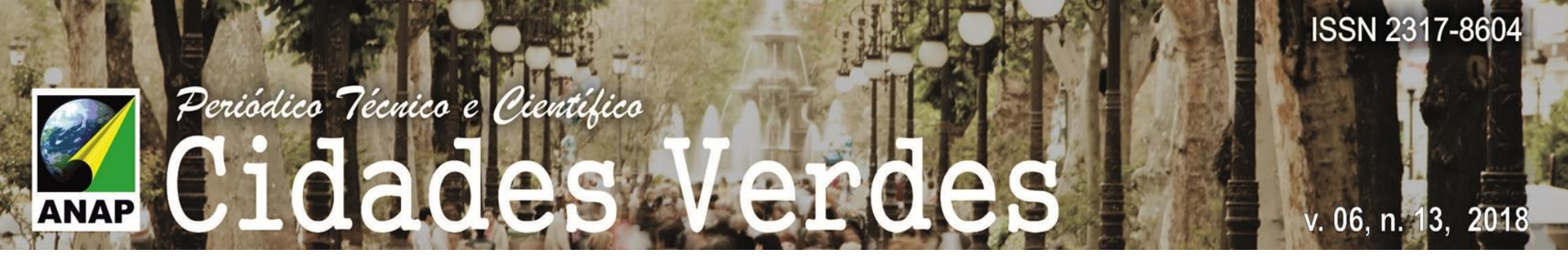

- Sistema de reuso da água (5\%)

- Sistema de aquecimento hidráulico solar (4\%)

- Construção com materiais sustentáveis (3\%)

- Plantio de mudas (4\%)

No município de Guarulhos-SP existe um desconto de 5\% a 20\% no IPTU de imóveis com área verde, captação de água da chuva, telhado verde e coleta seletiva previstos na Lei no 6.793/2011, observados os seguintes parâmetros:

- Acessibilidade - quem adaptar sua calçada para trânsito livre e seguro de pedestres e cadeirantes, mantendo de 1 a 1,5 metro para circulação terá desconto de até $5 \%$ no valor do IPTU;

- Arborização - os imóveis com uma ou mais árvores terão desconto de até $2 \%$ no valor anual do IPTU.

- Áreas permeáveis - Os imóveis horizontais com jardins ou gramados que permitam a absorção das águas das chuvas terão desconto de $2 \%$, e os condomínios terão desconto de até $1 \%$;

- Sistema de captação de água de chuva - 3\% de desconto;

- Sistema de reuso de água - 3\% de desconto;

- Sistema de aquecimento hidráulico solar - 3\% de desconto e sistema de aquecimento elétrico solar $3 \%$ de desconto;

- Construções com materiais sustentáveis - 3\% de desconto;

- Utilização de energia passiva (quando o projeto arquitetônico propicia o melhor aproveitamento da luz solar, dispensando o uso de ar condicionado e iluminação artificial) - 3\% de desconto;

- Utilização de energia eólica - 5\% de desconto;

- Telhado verde (vegetação em cima de todos os telhados da casa) - 3\% de desconto;

- Separação de resíduos sólidos (exclusivo para condomínios horizontais ou verticais que comprovadamente destinem sua coleta para reciclagem) - 5\% de desconto;

Salvador-BA oferece até $10 \%$ de desconto no IPTU àqueles que adotarem práticas sustentáveis em seus imóveis (Decreto 25.899/2015) e em Curitiba-PR, terrenos com áreas verdes garantem descontos de $10 \%$ a 100\% (Lei Complementar no 9.806/2000).

Deste modo, ainda que de maneira discreta, o Poder Público incentiva a participação da coletividade na proteção e preservação do meio ambiente estimulando a prática sustentável por meio de concessão de benefícios fiscais. 


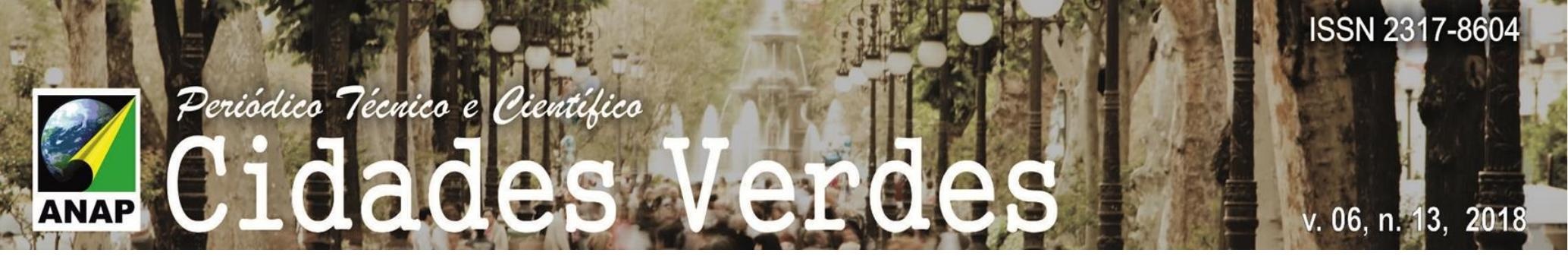

\section{CONCLUSÃO}

Diante de todo o exposto, é possível verificar de maneira bastante elogiosa que o legislador constituinte manifestou a preocupação com a preservação da sadia qualidade de vida, elevando ao status constitucional, a responsabilidade ambiental.

Não obstante os relevantes motivos que despertaram a necessidade de preservação ambiental, foi salutar dividir a responsabilidade entre o Poder Público em todas as suas esferas administrativas (União, Estados, Distrito Federal e Municípios) e o próprio povo, haja vista que de nada adianta o Poder Público tomar alguma atitude sem que a coletividade tenha alguma consciência dos impactos ambientais que suas atividades possam gerar.

Outrossim, não se pode perder de vista o princípio já consagrado da supremacia do interesse público em detrimento do interesse particular, principalmente quando se fala de meio ambiente, fundamental à própria existência humana e necessário para uma saudável qualidade de vida.

Quando se tem em mente os deveres institucionais do Estado, o bem comum acaba ganhando uma profunda ênfase em todos os seus aspectos, haja vista que o Estado foi idealizado para promover o bem de todos aqueles que dele fazem parte e, nada mais relacionado ao bem comum do que a preservação do meio ambiente ecologicamente sustentável.

Entre as mais diversas atitudes que o Estado pode adotar, dentre as quais as punições daqueles que degradam o meio ambiente, as medidas preventivas ainda são as mais eficazes e menos onerosas ao Poder Público.

A tributação é mecanismo necessário para manutenção do Estado e cumprimento de seus deveres institucionais, porém, também é uma medida interessante quando utilizada de modo a promover algum tipo de política social por meio da concessão de incentivos e benefícios.

Com a elevada carga tributária que é imposta à população brasileira, qualquer medida do ponto de vista da economia com o pagamento de tributos se mostra muito interessante, praticável, estimulante e, se for aplicada com vistas à preservação do meio ambiente, ainda atinge o objetivo constitucional de promover a educação ambiental e, quem sabe em um futuro não tão distante, ser um comportamento naturalmente incorporado na cultura brasileira.

Deste modo, fica evidente que o Estado tem tudo para promover a educação ambiental, a consciência ecológica e, não seria demasiado imaginar, alcançar o status de país ecologicamente sustentável, bastando a vontade política de promover essa cultura e a devida divulgação desses nobres ideais, incentivando ainda mais a preservação ambiental por meio de políticas de renúncia fiscal observadas as limitações constitucionais e regulamentadas na legislação infraconstitucional.

Tais renúncias não representariam qualquer tipo de irresponsabilidade com a arrecadação de recursos financeiros para manutenção do Estado, mas apenas e tão somente, economia com os futuros gastos que inevitavelmente deverão acontecer para reparar o grande mal que a sociedade faz a si mesmo por não compreender a necessidade de incorporar hábitos sustentáveis. 


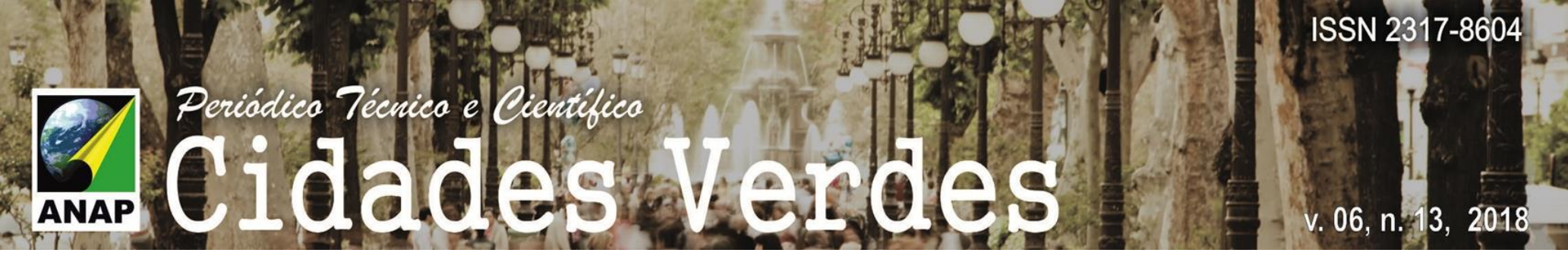

Os municípios que adotaram a simples forma de renúncia de um percentual de suas receitas com o IPTU, acabaram por gerar benefícios para a sua população a qual economiza recursos em diversos setores de seu orçamento e, indiretamente, promove a educação ambiental e conscientização com a sustentabilidade.

Instalação de placas fotovoltaicas não só podem gerar economia com o IPTU do imóvel, mas também a diminuição do valor na fatura de energia elétrica e o despertar para outras formas de energia limpa e renovável.

Incentivar o plantio de mudas por meio do incentivo fiscal pode colaborar no desenvolvimento da consciência ecológica nas crianças e a mudança de comportamento dos adultos que não tiveram acesso a uma educação ambiental na sua vida escolar e acadêmica.

Ao contrário do que pensa boa parte dos gestores públicos, isso não representaria renúncia de receitas ou, ainda, desperdício de dinheiro público mas ao contrário, significaria utilizar com inteligência uma necessidade pública impopular como a tributação de modo a fazer com que o cidadão se sinta inserido na gestão de sua cidade, economizar com futuros investimentos na reparação de degradações ao meio ambiente e, principalmente, promover a educação ambiental nos termos exigidos pelo texto constitucional.

\section{REFERÊNCIAS BIBLIOGRÁFICAS}

CARVALHO FILHO, José dos Santos, Manual de Direito Administrativo, 31a edição, São Paulo: Atlas, 2017

DALLARI, Dalmo de Abreu, Elementos de Teoria Geral do Estado, 25a edição, São Paulo: Saraiva, 2006

FERREIRA FILHO, Manoel Gonçalves, Curso de Direito Constitucional, 32a edição, São Paulo: Saraiva, 2006

PAPA JOÃO XXIII, Pacem in Terris (Encíclica, II, 58) disponível em http://w2.vatican.va/content/john-xxiii/pt/encyclicals/documents/hf j-

xxiii enc 11041963 pacem.html acesso em 14/05/2018 as 14h30min

Constituição da República Federativa do Brasil de 1.988 disponível em http://www.planalto.gov.br/ccivil 03/constituicao/constituicao.htm acesso em 14/05/2018

Lei de Responsabilidade Fiscal disponível em http://www.planalto.gov.br/ccivil 03/leis/lcp/lcp101.htm acesso em 14/05/2018

Sítio eletrônico da Receita Federal do Brasil http://idg.receita.fazenda.gov.br/ acesso em $14 / 05 / 2018$ 